Universidad de las Palmas de Gran Canaria, Spain

joseluis.zamora@ulpgc.es

\title{
THE SEX INDUSTRY IN ROMAN LAW: SOCIAL CATEGORIZATION OF PROSTITUTES
}

\section{LA INDUSTRIA DEL SEXO EN DERECHO ROMANO: CATEGORIZACIÓN SOCIAL DE LAS MERETRICES}

\begin{abstract}
Prostitution in Rome was socially accepted, the lenones were persecuted and their commercial activity and illegal exploitation that vilified women in a situation of vulnerability, a phenomenon that is a historical constant and that unfortunately today continues to reproduce, despite of the remarkable progress in the fight for networks of organized prostitution.

By the other hand the prostitution and the sex trade, is an activity that reproduces over time. In the present papier we will approach the figure of the meretrix from the point of view of a vulnerable group that performed an office under the "double moral" necessary to preserve the purity of the midwives, although it was socially marginalized when it was labelled as disgracefull. We will also see the exploitation suffered by many vulnerable women who were deceived and sexually exploited in brothels and private homes in a criminal network organized by pimps against which, as just like today, we had to fight with measures that the Roman administration undertakes to protect and finish of the sexual market.
\end{abstract}

\section{RESUMEN}

La prostitución constituye, desgraciadamente, un tema de enorme repercusión en la actualidad, sobre todo por las condiciones en las que viven miles de mujeres, que se dedican, hoy en día, a este oficio, muchas de ellas de forma forzosa y a través de redes 
de trata de blancas. En el presente trabajo abordaremos la figura de la meretriz desde el punto de vista de su categorización social como grupo vulnerable que realizaban su trabajo bajo la "doble moral" necesaria para preservar la pureza de las matronas, si bien fue socialmente marginada y estigmatizada como persona infame. También veremos la explotación que sufren muchas mujeres vulnerables que fueron engañadas y explotadas sexualmente en burdeles y hogares privados en una red criminal organizada por proxenetas, fenómeno que también se produce hoy en día.

El método utilizado es el histórico-crítico con el análisis de fuentes jurídicas y literarias que se refieren a las meretrices en Derecho romano.

Se observa como existe un paralelismo entre una problemática en el pasado y como, por desgracia, pervive en el Derecho vigente.

Se verifica una lucha continua contra la prostitución organizada desde el Derecho romano hasta la actualidad, se trata de una constante histórica

KEYWORDS: meretrix, dress code, lenocinium, sex industry, luparnar

Las palabras clave: meretriz, codigo vestimenta, lenocinium, industria del sexo, lupanar

El presente trabajo se enmarca dentro del proyecto DER 2016-78378-P del programa estatal de fomento de la investigación científica y técnica de excelencia, subprograma estatal de generación del conocimiento sobre: "La mujer en la Literatura y Jurisprudencia clásicas".

\section{INTRODUCCIÓN}

en Roma, la prostitución (Chatharine, 1997, 66 ss) llevo aparejada una serie de comportamientos que se estigmatizaban con la mera palabra y entre los cuales encontramos la explotación sexual y el trato degradante que padecían muchas mujeres, auténticas "esclavas sexuales" que proporcionaban muchos beneficios comerciales, haciendo que muchos se aventuraran en la industria del sexo.

Esta labor se desarrolló, principalmente, en los lupanares o burdeles, auténticos tugurios que se concentraban en los barrios de Subura y Velabro. Era una de las profesiones infamantes que, en el plano sociológico, se equiparaba a las profesiones ligadas al espectáculo como los actores (Neri, 1998, 199). 
Como señala Knapp (2011, 276 ss) no se puede idealizar románticamente con la vida de las prostitutas, las personas que la ejercían, mujeres libres o esclavas, eran sometidas, en numerosas ocasiones, a abusos físicos por parte de sus clientes. Además la lex Iulia et Papia prohibía el matrimonio de éstas con hombres libres, de ahí que fueran categorizadas socialmente como "feminae probosae" (Astolfi,1965, 15 ss). En las fuentes literarias encontramos alusiones a las que ejercían la prostitución, fueran libres o esclavas, como una profesión aberrante y vulgar, verbigracia, Plauto, Capt. 1029-1036 Spectatores, ad pudicos mores facta haec fabula est, / neque in hac subigitationes sunt neque ulla amatio/ nec pueri suppositio nec argenti circumductio / neque ubi amans adulescens scortum liberet clam suom patrem/ huius modi paucas poetae reperiunt comoedias,/ ubi boni meliores fiant. nunc vos, si vobis placet / et si placuimus neque odio fuimus, signum hoc mittite:/ qui pudicitiae esse voltis praemium, plausum date.

De igual manera, la vida licenciosa de las prostitutas o meretrices acarreaba deshonor y daba igual el lugar donde se realizara, sea éste lupanar (Lupanalupanus-lupanar) o burdel, o cualquier otro (Robinson, 1992, $138 \mathrm{ss)} \mathrm{como}$ ya hemos visto y también nos comenta Ulpiano en 1 ad legem Iuliam et Papiam, D.23.2.43.pr: Palam quaestum facere dicemus non tantum eam, quae in lupanario se prostituit, verum etiam si qua (ut adsolet) in taberna cauponia vel qua alia pudori suo non parcit.

Del texto ulpianeo, se observa como los lugares son desde el lupanar o burdel, como los locales más representativos, junto a los que se infieren de la cláusula edictal que recoge Ulpiano 6 ad Ed.,D.3.2.4.2. como las tabernae y los baños: Ait praetor: "qui lenocinium fecerit". lenocinium facit qui quaestuaria mancipia habuerit: sed et qui in liberis hunc quaestum exercet, in eadem causa est, sive autem principaliter hoc negotium gerat sive alterius negotiationis accessione utatur (ut puta si caupo fuit vel stabularius et mancipia talia habuit ministrantia et occasione ministerii quaestum facientia: sive balneator fuerit, velut in quibusdam provinciis fit, in balineis ad custodienda vestimenta conducta habens mancipia hoc genus observantia in officina), lenocinii poena tenebitur. En este sentido,es seguro que en las hosterías se desempeñaron actividades relacionadas con la prostitución donde la que regentaba el local hacía de alcahueta o lena como se infiere de otro fragmento 
de Ulpiano contenido en el mismo comentario, D.23.2.43.9: Si qua cauponam exercens in ea corpora quaestuaria habeat (ut multae adsolent sub praetextu instrumenti cauponii prostitutas mulieres habere), dicendum hanc quoque lenae appellatione contineri.

Volviendo a la categorización social, en términos generales, la prostituta es infame por el trabajo que realiza; además en la mayoría de los casos, se trata de esclavas bajo el dominio de un leno o lena, que favorecía los encuentros, mediando para satisfacer la lascivia de terceros a fin de obtener un lucro con el tráfico de éstas y su explotación (Sitek, 2004, s. 45).

La vestimenta marcaba un código( dress code) entre las mujeres que hacía que se diferenciaran las matronae con stola de las prostitutas con túnica corta, sin embargo, Plauto, nos comenta que las meretrices desafían la limitación de indumentaria con diferentes tipos de vestidos excéntricos... vesti quotannis nomina inveniunt nova?/tunicam rallam, tunicam spissam, linteolum aesicium, /indusiatam, patagiatam, caltulam aut crocotulam,/subparum aut subnimium, ricam, basilicum aut exoticum/cumatile aut plumatile, carinum aut cerinum - gerrae maxumae, Plauto, Epidicus, 229-233.

Con llegada del régimen de Augusto, el ambiente social de las mujeres comienza a ganar protagonismo y en el seno del matrimonio se producen cambios ya que con la promulgación de la lex iulia de adulteriis coercendis 18 a.C. se castiga cualquier relación fuera del matrimonio, llegando a ser considerada paradigma de la política moralizadora del emperador (Fernández de Buján, 2017, 87 ss); en la que además tipificó el adulterium, el incestum y el stuprum (Panero, 2009, 577 ss). La unión con una mujer núbil o viuda, virgo vel vidua, era considerada stuprum salvo en el caso de las mujeres in quas struprum non committtitur como las libertinae y las mujeres con costumbres livianas como las prostitutas, que socialmente eran marginadas por ser consideradas probosae y sufrir la infamia, privándolas, por tanto, de poder ser herederas de pleno derecho.

Ahora bien, se toleró y se promovió la prostitución como una actividad considerada necesaria, cumplía una "labor social", de ahí la "doble moral", ya que muchos preferían abandonarse a los placeres de la prostituta sin ningún tipo de carga o de responsabilidad, ya que no cabe duda de que era un bien para la socidad patriarcal que preservaba la castidad, honorabilidad y pureza 
de las matronas, si bien la meretriz era marginada socialmente, convirtiéndose en la "no mujer" (Montalbán, 2016, 174 ss). En este sentido, Catón el Viejo nos comentaba que: "es bueno que los jóvenes poseídos por la lujuria vayan a los burdeles en vez de tener que molestar a las esposas de otros hombres"; es decir, consideraba que la actividad de los próstibulos eran necesarias; igualmente, también es mencionado por Horacio Serm.1.2.31:

quidam notus homo cum exiret fornice, 'macte/ virtute esto' inquit sententia dia Catonis;/'nam simul ac venas inflavit taetra libido/ huc iuvenes aequom est descendere, non alienas/ permolere uxores.' 'nolim laudarier' inquit; dónde Catón, al encontrarse a un joven saliendo de un lupanar, alaba que lo que hacía señalando que: “... así cuando el deseo te hinche las venas no abusarás de las mujeres decentes", si bien matizando que "no debe abusar y considerarlo como casa".

El barrio de peor fama era el Subura, donde los propios habitantes de los barrios prostituían a sus hijas y sus mujeres para sobrevivir y hacer frente a su sustento. Plauto describe estas prostitutas deambulantes del barrio como mujeres carentes de belleza o recato, poen.v. 265-270:

Turba est nunc apud aram. an te ibi vis inter istas versarier/ prosedas, pistorum amicas, reliquias alicarias,/miseras schoeno delibutas servolicolas sordidas,/ quae tibi olant stabulum statumque, sellam et sessibulum merum,/quas adeo hau quisquam umquam liber tetigit neque duxit domum,/servolorum sordidulorum scorta diobolaria?

Asimismo, Horacio, en su percepción epicúrea de la vida, también alude a la importancia de la prostitución como alternativa al adulterio, veamos algunos de sus versos. El autor venusino se centra en el hecho de no corromper a mujeres ajenas mediante relato descriptivo haciendo alusiones a la prostitución como un medio de desahogo asequible (namque parabilem amo venerem facilemque (Serm. I.2.119), a pesar de las condiciones de los lupanares... sunt qui nolint tetigisse nisi illas/ quarum subsuta talos tegat instita veste,/contra alius nullam nisi olenti in fornice stantem...(Serm. I.2.28-30) "los hay quien solo querrían tocar a mujeres cuyos talones cubre vestido con volantes, en cambio, otro sólo a inquilina de mal oliente lupanar...”.

Además, Horacio, al hablar de las relaciones eróticas, señala que se deben evitar las matronas las mujeres de otros: Nil fuerit mi inquit cum uxoribus 
unquam alienis/ verum est cum mimis, est cum meretricibus, unde/ fama malum gravius quam res trahit. Serm.I.2.57-58. Con ironía benévola, el autor va respondiendo a la función de las prostitutas y como éstas carecen de los inconvenientes sociales y legales del adulterio, sobre todo cuando puede uno ser cogido in fraganti: Serm. I.2.123-129:

"..candida rectaque sit, munda hactenus, ut neque longa/ nec magis alba velit quam dat natura videri./ haec ubi supposuit dextro corpus mihi laevom,/ Ilia et Egeria est; do nomen quodlibet illi/nec vereor, ne, dum futuo, vir rure recurrat,/ianua frangatur, latret canis, undique magno/ pulsa domus strepitu resone...."

Los pasajes de Horacio, a través de su discurso literario tamiza y encauza la figura de las meretrices desde su género poético haciendo mención expresa de las formas que tenía el hombre romano de las tentaciones, evitando recurrir a una falta moral que implica poner en peligro la pudicitia de las mujeres decentes o modélicas. Por ello, la prostitución era una necesidad, un remedio que preservaba la moralidad y fidelidad de las matronas (Vanoyeke, 1990, 77 ss) ya que, éstas últimas, se convertían en pieza clave de la institución del matrimonio (Sitek, 1999, s. 62).

En sentido estricto, las meretrices eran las que actuaban normalmente en la vía pública, si bien existían aquellas que eran mesoneras y otras que eran más complacientes y elegantes, las cortesanas, éstas últimas ejercían la prostitución en los círculos sociales más elevados. Sin embargo, lo más frecuente eran aquellas meretrices ligadas a su leno o lena que se encargaba de explotarlas sexualmente, sabiendo que, en la sociedad romana, no existía una reprobación por este tipo de relaciones, autentico modus vivendi, en las que se producía esa fascinación por lo prohibido.

Desde el punto de vista de la intervención normativa, como veremos, existe una estrategia regulacionista al estar permitida, una infamia necesaria que garantizaba un orden establecido aceptado, como tal, por el ciudadano romano, a pesar de que la prostituta en si misma estuviese discriminada y marginada. Es evidente que la meretriz, cortesana o prostituta es la que se gana la vida a través de su cuerpo, si bien la tarea de definirla es importante para deslindar la prostitución de otras formas de relación no marital que operaban en roma como el concubinato o el adulterio (McGinn, 1998, 
17 ss). De ahí que haya que distinguir los tres criterios que hemos apuntado para saber a qué nos referimos en relación a esta forma de exhibición sexual en la que la prostitución, a pesar de la doble moral romana, constituye una de las prácticas más solicitadas y en la que, en el siglo II a. C., Catón, a pesar de su defensa acérrima de los mos maiorum, veía en ella algo positivo ya que era una forma de impedir poner en peligro a las mujeres libres y su pudicitia, si bien la mujer que transgredía el prototipo femenino de matrona púdica era denominada con diferentes calificativos(Molina Torres, 2016, 61 ss), que no dejan de ser eufemismos que proceden de préstamos de otras lenguas como el griego; así, encontramos denominaciones genéricas como meretrix, scortum y quaestuaria o quaestuosa (Quintilla Zanuy, 2004, 103 ss) y otras en relación al:

- lugar entre la prostituta de burdel (fórnix, ganea, proseda, prostibulum, prostibula, prostibulata, prostituta, sellaría) incluso otro tipo de locales (popa, caupona, tibicina) o la propia calle (erratica scorta, circulatrix).

- beneficio o dinero que obtenía (argentaria elecebra, diobolaris, quadrantaria).

- a su aderezo personal y físico (relquia, alicaria, schoenicula, togata, culiola, culibonia).

Ahora bien, la prostitución como tal, estaba tolerada e integrada en la estructura social, ya que era necesaria para cumplir un fin social, sanar los impulsos de fines libidinosos del hombre y, por ende, el matrimonio y el orden establecido, siendo la prostituta una turpe persona, tachada de infame. Pero a pesar de esto, las acciones de las prostitutas no eran ilegales, a ello se une un registro de prostitutas y el cobro de un impuesto que éstas debían de pagar, luego en cierta medida existía un control del oficio y un aprovechamiento de la propia Administración de los ingresos que se generaban por esta industria del sexo.

Se tutelaba el pago recibido por éstas como se infiere del fragmento de Ulpiano, 26 ad ed. D.12.5.4.3.:

Sed quod meretrici datur, repeti non potest, ut Labeo et Marcellus scribunt, sed nova ratione, non ea, quod utriusque turpitudo versatur, sed solius dantis: illam enim turpiter facere, quod sit meretrix, non turpiter accipere, cum sit meretrix. 
En el texto se habla precisamente de la no repetición del pago realizado a la meretriz por parte de Ulpiano acogiendo el parecer de Labeón y Marcelo; sin embargo, al margen de la compensación económica por los servicios prestados que son reconocidos, se establece claramente la expresión "illam enim turpiter facere, quod sit meretrix" que hace que la prostituta lleve aparejada la tacha de infamia y de persona torpe. La categorización social de turpes personae afectaba además de las prostitutas, los actores y los gladiadores, Calistrato 3 ed. mon., D.38.1.38.pr: Hae demum impositae operae intelleguntur, quae sine turpitudine praestari possunt et sine periculo vitae. Nec enim si meretrix manumissa fuerit, easdem operas patrono praestare debet, quamvis adhuc corpore quaestum faciat: nec harenarius manumissus tales operas, quia istae sine periculo vitae praestari non possunt.

Este aspecto moral no importaba a las autoridades, al fin y al cabo este tipo de relaciones no infringían ninguna ley, solo tenía una serie de consecuencias su vida licenciosa, además de ser consideradas probosae, no podían redactar testamentos ni ser herederas de pleno derecho. Esto hacía que se consideraran como malum exemplum, sin embargo, el negocio del lenocinio fue necesario tal y como hemos apuntado, por motivos socioeconómicos integrándose en el tejido urbano como un oficio mas.

\section{CATEgorización SOCIAL DE LA PROSTITUTA Y SU EXPLOTACIÓN SEXUAL}

Como ya hemos señalado con anterioridad, la prostituta hacía ganancia con su propio cuerpo corpore quaestum facere, su ejercicio no estaba penado ni tan siquiera podía ser procesada porque el ejercicio era legal, y afectaba a todas las clases sociales aunque fue mas frecuente el ejercicio por parte de aquellas que estaban en situación vulnerable y de pobreza, si bien también encontramos aquellas que ejercitaban la prostitución por el simple hecho de disfrutar del sexo sin ningún tipo de atadura, evitando la sanción legal. Como ya vimos en relación a que el sexo con la meretrix no comprometía ni ponía en peligro la consanguinidad de la familia; al fin y al cabo, las relaciones con éstas no infringían ninguna ley o costumbre moral porque no eran sancionadas ni como adulterio ni como stuprum, en las leyes del matrimonium en particular la lex iulia de adulteriis coercendis 18-16 a.C ni la de maritandis ordinibus que 
tan solo prohibían el matrimonio con mujeres de mala reputación a fin de salvaguardar la salus rei publicae, si bien ,la propia legislación contenía otras disposiciones cuyo fin fue el de favorecer la natalidad.

Las prostitutas podían ser libres o esclavas y un aspecto común a ambas era el maltrato y los abusos sexuales a las que se veían sometidas por parte de sus clientes que provocaban numerosas lesiones vaginales y anales, así como infecciones del trato urinario. En el ámbito de las esclavas prostitutas (ancillae) estas sufrían los abusos y secuestros con fines sexuales evitando sus raptores pagar el precio.

La indumentaria de la prostituta era significativa, de hecho justificaba que en ocasiones se produjese violencia sexual por el atuendo como se puede inferir en la regulación de los supuestos de edicto de ademptata pudicitia, en el que encontramos un tipo de injuria, aunque el texto utiliza el verbo apellare como referido a dirigir palabras para hacer proposiciones deshonestas (Escutia Romero, 2010, 74), en concreto veamos el pasaje de Ulpiano 72 ad ed., D.47.10.15.15, contenido en la rúbrica De iniuriis et famosis libellis: Si quis virgines appellasset, si tamen ancillari veste vestitas, minus peccare videtur: multo minus, si meretricia veste feminae, non matrum familiarum vestitae fuissententiarum si igitur non matronali habitu femina fuerit et quis eam appellavit vel ei comitem abduxit, iniuriarum tenetur.

El texto va referido a doncellas virgines, que ocupan una posición social respetable pero socialmente de nivel inferior a las matronas. Por consiguiente, Ulpiano parece establecer en su comentario edictal que tipo de mujeres estaban protegidas frente a este tipo de adtemptata pudicitia. Y como el rango social lo determinaba también la vestimenta, dónde el tipo de indumentaria distinguía la mujer respetable y honorable de la que no lo era, es decir la sociedad contaba con un dress code que identificaba. El fragmento habla de dos de las conductas del edicto apellare que va referido a dirigir palabras inmorales pero no turpitus verbis sino "blanda oratione", con palabras que atenten contra la honestidad pero sin utilizar expresiones obscenas. A su vez, tampoco se habla de adsectari que era perseguir y asediar de forma insistente, si bien estaría incluida esta conducta, junto a la que si se comenta de forma expresa que es la de comitem abducere, es decir, la de alejar o quitar al acompañante y por tanto exponerla a un peligro porque se la deshonraba con esa actitud exponiéndola a dejarla sola en la calle. 
Por otro lado, avanzando en nuestro razonamiento debemos considerar si el comportamiento de la mujer que utiliza prendas inapropiadas constituye una ofensa moral contra los cánones de los boni moris, en este sentido la respuesta debe ser afirmativa, motivo por el cual al exigirse una conducta y apariencia, la misma puede quedar desvirtuada por el uso de tales prendas, de ahí que de conformidad con lo establecido en el pasaje no se pueda reclamar por ese acoso que probablemente implicaba esa violencia a la que hemos aludido al ser considerado multo minus, si meretricia veste feminae, lo cual implica, que la mujer goza de una gran restricción relativa a su libertad de movimientos teniendo que soportar además el acoso y las agresiones sexuales, incluso en los supuestos en los cuales sea discutida la indumentaria, como sucede con el caso de las esclavas, ya que el fragmento habla de menor culpa minus peccare, a sabiendas de que no deja de ser un acoso, lo cual es a mi juicio una causticidad por parte de Ulpiano.

En base a lo antedicho, se observa que la forma de vestir es importante en orden a determinar la conducta punible del agresor, ya que el atacante no podría aducir desconocimiento o ignorancia del estatus de la persona que la sufría si no iba vestida de conformidad con su rango social (Bravo Bosch, 2017, 211 ss), donde, en el caso de mujeres ilustres, normalmente, vestían con la stola o la toga praetexta. Por ello, consideramos que estamos en presencia de una violencia sexual y un atentado contra la mujer, que parecía quedar justificado por el dress code al estar relacionado con aquellas mujeres que ejercían la prostitución en una ciudad bulliciosa como Roma, donde los transeúntes de cualquier condición se mezclaban y en la que la indumentaria, servía para distinguir el status de la población; en este sentido las propias cortesanas, estaban obligadas a vestirse con elegancia y bien ataviadas, portando algún tipo de elemento ornamental que las distinguía de las matronas.

Es obvio que la explotación implicaba lucrarse con la prostitución ya sea de esclavos o personas libres, como ya vimos ab initio en D.3.2.4.2 referido al que hace lenocinio: no solo el que hubiera tenido esclavos para lucrarse con su explotación sexual, sino también el que realiza esta actividad con personas libres. Otra de las cuestiones que destaca el fragmento es que dicha actividad se puede realizar directamente, es decir, habilitando locales a tal efecto bien 
con cella meretriciae o lupanares estos últimos con escasa intimidad según nos informan algunas fuentes; o de forma indirecta, como ya hemos apuntado anteriormente, aprovechando el uso de otra actividad comercial. Pero lo significativo es que esta regulación edictal parte de cuando era considerado el lenocinio, antes de la lex iulia de adulteriis coercendis, como infamia notatur... qui lenocinium fecerit. Juliano 1 ad ed., D.3.2.1.

Es necesario recalcar que el negocio del sexo daba rentabilidad de ahí que fuese normal aprovechar posadas, tabernas y baños; de hecho fue frecuente que se desempeñara la profesión de camarera y prostituta a la vez, y en las que normalmente encontramos la figura de la lena o alcahuetas encargadas de captar a los clientes. Se observa que las fuentes tratan el lenocicio desde la perspectiva de la ganancia o lucro que obtienen las personas que lo cometen. Y, por tanto, se produce con la obtención de beneficios con la prostitución ajena, ya sean esclavos o libres, directamente o a través de otros negocios que se podían utilizar de tapadera para el ejercicio del lenocinio, sive autem principaliter hoc negotium gerat sive alterius negotiationis.

Hay que mencionar además que la explotación también podía ser realizada directamente por esclavos, como nos informa el pasaje de Ulpiano 4 ad ed., D.3.2.4.3 que, citando a Pomponio, señala: et eum, qui in servitute peculiaria mancipia prostituta habuit, notari post libertatem ait. Esto es, el esclavo que se lucra con la prostitución de otros esclavos, acto indigno y por tanto reprobable que implica la comisión de lenocinio cuando este obtenía su condición de sujeto libre, y que implicaba en un primer momento, la nota de infamia antes señalada.

Es evidente que la prostitución supuso la victimización de la mujer y la mercantilización de su cuerpo. Los motivos de su ejercicio no solo eran de forma voluntaria por indigencia y necesidades económicas o forzosa a través de la explotación por parte de proxenetas, sino también algunas mujeres lo hacían de forma voluntaria para poder sustraerse a legislación augústea y así carecer de los inconvenientes sociales y legales del adulterio, de ahí que muchas veces fueran inscritas de forma voluntaria en el registro que se habilitó a tal efecto, incluso algunas viudas. Este abuso, según el cual algunas eran inimputables por esa inscripción en ese registro de meretrices, hizo que se promulgara un Senadoconsulto en época de Tiberio que es recordado por Papiniano, 2 adult. en D.48.5.11 (10).2: 
Mulier, quae evitandae poenae adulterii gratia lenocinium fecerit aut operas suas in scaenam locavit, adulterii accusari damnarique ex senatus consulto potest.

Según se infiere de la opinión del jurista, la mujer que para evitar la pena de adulterio hubiera cometido lenocinio o arrendado sus servicios para el teatro puede ser acusada y condenada por adulterio, la finalidad de este Senadoconsulto es obvia: frenar el fraude y controlar la moralidad pública.

Por otro lado, debemos agregar que existen mujeres y niñas que eran secuestradas por bandas armadas y piratas y que, finalmente, eran vendidas a un proxeneta para ser explotadas; así sucede con Carites que intenta escapar y finalmente es vendida para ser explotada en un burdel, en vez de ser asesinada por sus captores, como nos informa Apulelyo en su Asinus aureus o Metamorfosis, Apuleyo, Metam. 7.9: Quin ego censeo deducendam eam ad quampiam civitatem ibique venundandam. Nec enim levi pretio distrahi poterit talis aetatula. Nam et ipse quosdam lenones pridem cognitos habeo, quorum poterit unus magnis equidem talentis, ut arbitror, puellam istam praestinare condigne natalibus suis fornicem processuram nec in similem fugam discursuram, non nihil etiam, cum lupanari servierit, vindictae vobis depensuram. Hanc et animo quidem meo sententiam conducibilem protuli; sed vos vestrorum estis consiliorum rerumque domini.

Pero muchas veces, son las propias madres las que convertían a sus propias hijas en prostitutas ante situaciones de hambruna, o, incluso, los padres que forzaban y explotaban sus propias hijas como prostitutas a fin de obtener beneficos. Todo ello convertía a la "industria del sexo" en Roma como un negocio de alta rentabilidad de ahí la importancia de reclutar prostitutas para los burdeles que van a ser explotados por lenos o rufianes, y que muchas veces encontrábamos a niñas que eran adiestradas para ser las perfectas cortesanas. Sobre el diálogo de Parmenon, Tais y Fedro, señala que un mercader le entrego una niña raptada en Ática que como era demasiado pequeña es entregada a una madre a la cual se la informa de la procedencia de la niña por lo que los piratas habían comentado al mercader. El caso es que la niña es educada probablemente para el ejercicio ulterior de la profesión, Terencio, Eunuc. 107-117: 
Samia mihi mater fuit: ea habitabat Rhodi./ PA. potest taceri hoc. TH. ibi tum matri parvolam/ puellam dono quidam mercator dedit/ ex Attica hinc abreptam. PH. civemne? TH. arbitror;/ certum non scimu': matri' nomen et patris/ dicebat ipsa: patriam et signa cetera/ neque scibat neque per aetatem etiam potis erat./mercator hoc addebat: e praedonibus,/unde emerat, se audisse abreptam e Sunio/mater ubi accepit, coepit studiose omnia/ docere, educere, ita $u t<i>$ si esset filia./ sororem plerique esse credebant meam.

Como seña Vanoyeke $(1990,91)$ el leno tenía sus prostitutas por categorías, atribuyendo a cada una la tarea de ocuparse de un oficio concreto, buscando sobre todo comerciantes romanos o extranjeros para que paguen en especie, para proporcionarle a éste bienes y alimentos. De esta forma, se observa la codicia del leno que es capaz de abandonar a la prostituta de escasa rentabilidad, en una pergula. De ahí que, éste, siempre controlase el precio de los servicios , escogiendo siempre al mejor postor. Por ello, eran considerados personas sin escrúpulos que trataban de obtener la máxima inversión a través de la explotación de la esclava o de las mujeres libres, obteniéndose así ganancias con su cuerpo, quae corpore questum facit, perífrasis con la que se suelen referir a estas meretrices y que Ulpiano, ad leg. Iul. et. Pap., D.23.2.43.6 lo equipara al lenocinio: lenocinium facere non minus est, quam corpore quaestum exercere.

Por otra parte, el mismo jurista nos informa de quienes eran las lenae en 23.2.43.7: estableciendo Lenas autem eas dicimus, quae mulieres quaestuarias prostituunt; esto es, a las que prostituyen a las mujeres o incluso en el parr. 8 a las que lo hacen en nombre de otro que hace este tipo de explotación, sea leno o lena: accipiemus et eam, quae alterius nomine hoc vitae genus exercet; cuando el texto habla en nombre de otro puede entenderse referido a aquellos que se implican de forma indirecta, ya sea de forma habitual o esporádica. Si bien, es evidente que había un ejercicio.

Además, en el fragmento 9 se alude a lo que antes comentábamos de negocio encubierto y de, como hemos visto en las fuentes, manera frecuente, como es el caso de la posada que se usa como burdel:

Si qua cauponam exercens in ea corpora quaestuaria habeat (ut multae adsolent sub praetextu instrumenti cauponii prostitutas mulieres habere), dicendum hanc quoque lenae appellatione contineri; no en vano muchas camareras y posaderas ejercían la prostitución en estos locales. 
Daba igual el ejercicio público de la prostitución como vimos en el fragmento D.23.2.43.pr: Palam quaestum facere dicemus non tantum eam, quae in lupanario se prostituit, verum etiam si qua (ut adsolet) in taberna cauponia vel qua alia pudori suo non parcit; al cual se alude con la expresión palam ya que también sucedía lo mismo cuando esta se realizaba fuera de un lupanar, bodega o, incluso, baños públicos como se infiere del texto de Pomponio, 4 ex Plaut., D.23.2.41.pr: probrum intelligitur etiam in his mulieribus ese quae turpiter viverent, vulgoque questum facerent, etiamsi non palam.

Ahora bien, esta expresión "palam" también aparece referida en el fragmento D.23.2.43.1 (Ulpiano ad legem Iul. et Pap.): Palam autem sic accipimus passim, hoc est sine dilectu: non si qua adulteris vel stupratoribus se committit, sed quae vicem prostitutae sustinet.

En este caso interpretamos "públicamente" en el sentido de que las meretrices no tenían posibilidad de elegir, frente al adulterio o estupro donde la mujer tiene capacidad decisoria(Panero Oria, 2002, 783 ss). Si bien, debemos adicionar que la mujer por el hecho de recibir dinero, por entenderse con uno o con otro, no le confiere la condición de prostituta porque parece ser que también existe una forma voluntaria como se infiere del frag. 2: Item quod cum uno et altero pecunia accepta commiscuit, non videtur palam corpore quaestum facere.

De esta forma, parece evidente que la omisión de la expresión "palam = públicamente", se interpreta por el hecho de que se puede prostituir sin dinero, a fin de satisfacer su apetito sexual.

Indiscutiblemente, aunque el lenocinio o alcahuetería, inicialmente se conmina dentro de la infamia pretoria, con posterioridad, con la promulgación de la lex iulia de adulteriis, se tipifica esta figura criminosa, si bien la lex sanciona y reprime el adulterium. Ello se debe a que la ley configura la quaestio (Brasiello, 1937, 61 ss) para aquellas conductas que relacionan el lenocinium con el adulterio y que son el lenocinium mariti, el lenocinium uxoris y el lenocinium de quien contrae matrimonio con una mujer condenada por adulterio.

De igual modo, nos interesa la posible explotación que hace el marido de su mujer a través de un adulterio consentido por éste a cambio de una ganancia. Si bien queremos matizar una cuestión importante, la expresión 
de crimen lenocinii, en este punto, al margen de la alcahuetería que , como vimos antes, va referida a adquirir un lucro de una unión sexual sancionadas con la lex iulia de adulteris, existen otras conductas que tratan de encubrir el adulterio y el estupro. En estas líneas solo nos vamos a centrar en las que se equiparan al meretricio.

Esta modalidad de lenocinio en relación al adulterio viene conceptualizada por Ulpiano, 1 de adulteriis, en el fragmento D.48.5.2.2: Lenocinii quidem crimen lege Iulia de adulteris praescriptum est, cum sit in eum maritum poena statuta, qui de adulterio uxoris suae quid ceperit, item in eum, qui in adulterio deprehensam retinuerit.

En el fragmento el jurista establece las conductas que son constitutivas de lenocinium mariti que son dos: la primera, que es la que nos interesa en relación al que obtiene ganancias por el adulterio de su mujer y la segunda el supuesto del marido que no repudia a su mujer cuando esta es sorprendida cometiendo adulterio. Desde nuestra perspectiva, nos incumbe el primer supuesto en el que el marido obtiene ganancias (quaestum) ejerciendo lenocinium con su propia mujer, ya que dicho comportamiento es deplorable, de ahí que se establezca que dicha actuación del marido sea nec enim mediocritet deliquit Ulpiano 1 de adulteriis, D.48.5.30(29).3. Este comportamiento es equiparable al ejercicio de la prostitución y, por tanto, el marido actúa como leno, obteniendo un lucro que tipifica el hecho punible tolerando la infidelidad de la mujer que actúa como si fuera una meretriz, uxorem pateretur adulterari meretricio quodam genere, (Rizzelli, 1997, 139) siendo indiferente si la actividad se realiza de forma espontánea o es habitual como nos ofrece el pasaje contenido en D.48.5.30(29).4:

Quaestum autem ex adulterio uxoris facere videtur, qui quid accepit, ut adulteretur uxor: sive enim saepius sive semel accepit, non est eximendus: quaestum enim de adulterio uxoris facere proprie ille existimandus est, qui aliquid accepit, ut uxorem pateretur adulterari meretricio quodam genere. Quod si patiatur uxorem delinquere non ob quaestum, sed neglegentiam vel culpam vel quandam patientiam vel nimiam credulitatem, extra legem positus videtur.

Creemos que el marido pudo explotar a la propia mujer y ante dicha situación de abuso era condenado por al lex iulia de adulteriis. Existía una 
excepción como recoge el final del fragmento en los casos en los que no concurría ganancia y sea debida a negligencia, culpa, tolerancia o demasiada credulidad; supuestos en los que quedaba excluida la aplicación de la ley.

Cabe señalar también que se castigó también el favorecer la comisión de otras conductas como el stuprum o el adulterium, proporcionando habitación o lugar para poder llevar a cabo dicha relación ilícita, a cambio de lucro, pero no es considerada ex causa lenocinii, como se infiere de los fragmentos de Papiniano 2 de adult, D.48.5.9(8)pr y de Ulpiano 4 de adult. D.48.5.10 (9) pr.

Igualmente, se castigaba a la mujer que facilitaba casa para la realización de las conductas tipificadas por la lex iulia de adulteriis: Mulieres quoque hoc capite legis, quod domum praebuerunt vel pro comperto stupro aliquid acceperunt, tenentur. Estos últimos pasajes obedecen al favorecimiento de dichas conductas y como veremos más adelante en la Nov.14 se alude de forma específica a habitáculos donde se ejercía la explotación sexual de mujeres en situación vulnerables por parte de proxenetas y que no tenían por que producirse siempre en lupanares.

La explotación sexual a la que podían quedar sometidas por los padres o los lenones es castigada a raíz de la influencia del cristianismo, a partir de ese momento encontramos una serie de disposiciones que tratan de poner freno a estas situaciones. En este sentido es bastante explícita la Constitución de Teodosio y Valentiniano del 428 dirigida a Florentino Praefectus praetorio recogida en CTh. 15.8.2 y reproducida de forma sucinta en C.11.41.6 y C.1.4.12:

Lenones patres et dominos, qui suis filiis vel ancillis peccandi necessitatem imponunt, nec iure frui dominii nec tanti criminis patimur libertate gaudere. Igitur tali placet eos indignatione subduci, ne potestatis iure frui valeant neve quid eis ita possit adquiri. Sed ancillis filiabusque, si velint, conductisve pro paupertate personis, quas sors damnavit humilior, episcoporum liceat, iudicum etiam defensorumque implorato suffragio omni miseriarum necessitate absolvi, ita ut, si insistendum eis lenones esse crediderint vel peccandi ingerant necessitatem invitis, non amittant solum eam quam habuerant potestatem, sed proscripti poenae mancipentur exilii metallis addicendi publicis, quae minor poena est, quam si praecepto lenonis cogatur quispiam coitionis sordes ferre, quas nolit.

Se observa que dichos actos son considerados un crimen grave como se infiere de la expresión "criminis patimur libertate gaudere» a la vez que 
se aprecia que el comercio y la explotación sexual de las hijas o esclavas es considerado "peccatum (peccandi necessitatem)» (Biondi, 1952, 277). Se habla precisamente de personas vulnerables que han sido obligadas al ejercicio de la prostitución por su condición social. Esta situación misérrima, a pesar de que era ilegal como señala McGinn $(2004,56)$, no dejaba de producirse en la praxis, de ahí la justificación de la disposición por la cual a través del auxilio de los obispos, jueces y defensores se proteja a estas personas vulnerables frente al abuso no sólo de los proxenetas sino también de los padres, privándoles a éstos de la patria potestad y de la propiedad, conminándolos con pena de destierro con destino a una mina pública, in metallis addicendi publicis, penas que son consideradas inferiores al suplicio que supone la explotación sexual forzada que hace el leno quam si praecepto lenonis cogatur quispiam coitionis sordes ferre, quas nolit. En todos estos supuestos, se permite la intervención de las autoridades citadas para luchar contra la prostitución a la que eran forzadas muchas hijas y esclavas.

\section{VULNERABILIDAD, ABUSO Y MEDIDAS CONTRA LOS PROXENETAS}

La situación de vulnerabilidad de las meretrices que se veían explotadas por los proxenetas organizados en auténticas redes de trata de blancas fueron objeto de cierta protección frente a la codicia de estos, y así, como nos comenta el cronista bizantino Juan Malalas: Ioh. Mal. Chron 13.39"Veneris autem Fanum in Carrucarium fecit Preafecto Praetorio; constructisque in circuitu Hospitiis, paperculuas ibi meretrices gratis commorari jussit”. El emperador Teodosio I llega a conceder alojamiento gratuito a las prostitutas indigentes construyendo a tal efecto viviendas alrededor del tempo de Venus que se había convertido en un depósito de carros del prefecto Pretorio. Se favorecía así el que estas meretrices ejercieran la prostitución de forma libre sin ningún tipo de vinculación a los prostíbulos donde podían ser explotadas sexualmente por proxenetas; así en Historia Augusta, se narra la vida de Heliogábalo en relación a la prostitución, la tasa y los lugares de de libertinaje Heliog. 25.5 "meretrices a lenonibus cunctis redemit saepe et manumisit", 26.3 "Omnes de Circo, de theatro, de Stadio, et omnibus locis et balneis meretrices collegit in aedes publicas et apud eas contionem habuit quasi militarem, dicens 
eas conmilitones disputavitque de generibus schematum et voluptatum." 27.7 "iusserat et canonem populi Romani unius anni meretricibus, lenonibus, exsoletis intramuranis dari, extramuranis alio promisso, cum eo tempore iuxta provisionem Severi et Traiani septem annorum canon frumentarius Romae esset" y 31.6 "causa vehiculorum erat lenonum, lenarum, meretricum, exsoletorum, subactorum etiam bene vasatorum multitudo".

Nos encontramos con un texto significativo sobre la explotación sexual en el que no se pretende reprimir la prostitución sino el lenocinio como crimen y en el que se habla de un problema que sigue produciéndose en la actualidad como es el tráfico de seres humanos con fines sexuales. El pasaje en cuestión es la Novela 14 de Justiniano en la cual se describe con todo lujo de detalles el reclutamiento y la comercialización de prostitutas por parte de los proxenetas que intentan obtener nefandos lucros a través de un negocio que degrada la condición del sujeto y que desgraciadamente en la actualidad se sigue produciendo. Esta constitución datada en el año 535 trata de perseguir el lenocinio a fin de salvaguardar el pudor y la integridad de las mujeres que se encontraban en situación de vulnerabilidad.

Veamos la Novela 14 el Prefacio de la novela dirigida a los constantinopolitanos, habitantes de una magna metrópolis en la cual existe corrupción y conflictos sociales, trata de concienciar a la población como expresa el texto de la novela antes una serie de denuncias que se presentan en relación a una serie de comportamientos ilícitos e impíos (Harper, 2013, 234 ss) "rerum impiarum pro talibus negotiis" en los que el comercio clandestino de los proxenetas debía ocupar, en Constantinopla, uno de sus problemas centrales, veamos el texto: Et antiquis legibus et dudum imperantibus satis odibile visum est esse lenonum nomen et causam, in tantum ut etiam plurimae contra talia delinquentes scriberentur leges. Nos autem et dudum posita contra eos qui sic impie agunt supplicia auximus, et si quid relictum est a nostris praecessoribus, etiam hoc per alias correximus leges, et nuper interpellatione nobis facta rerum impiarum pro talibus negotiis in hac maxima civitate commissis causam non despeximus. Agnovimus enim quosdam vivere quidem illicite, ex causis autem crudelibus et odiosis occasionem sibimet nefandorum invenire lucrorum, et circuire provincias et locaplurima et iuvenculas miserandas decipere promittentes calciamenta et vestimenta quaedam, et his venari eas et deducere ad hanc 
felicissimam civitatem et habere constitutas in suis habitationibus et cibum eis miserandum dare et vestem et deinceps tradere ad luxuriam eas volentibus, et omnem quaestum miserabilem ex corpore earum accedentem ipsos accipere et celebrare conscriptiones, quia usque ad tempus, quod eis placuerit, observabunt impiam et scelestam hanc functionem implentes; quasdam vero earum etiam fideiussores expetere. Et in tantum procedere illicitam actionem, ut omni paene in hac regia civitate et in transmarinis eius locis et (quod deterius est) iuxta sacratissima loca et venerabiles domos tales sint habitationes, et causae sic impiae et iniquae sub nostris temporibus praesumantur, ita ut etiam quosdam miserantes earum et abducere a tali operatione crebro volentes et ad legitimum deducere matrimonium non sinerent. Quosdam autem sic scelestos existere, utpuellasnecdecimumagentesannumadpericulosam deponerentcorruptionem; et quosdam aurum dantes non parvum vix inde redemisse miseras, et nuptiis copulasse castis...

El prefacio se dirige a poner de relieve la difusión de una red organizada de trata de blancas (Rodríguez Lopez, 2018, 263 ss) al señalar el procedimiento de reclutamiento de las mujeres en situación de vulnerabilidad, la cual es aprovechada para la obtención de un lucro por parte de los proxenetas. Para ello, como señala el texto, se valen de artimañas en las que recorriendo las provincias buscando jóvenes en situación de pobreza, iuvenculas miserandas, ofrecen calzado y vestidos como señuelo para luego recluirlas en habitaciones a fin de ser explotadas sexualmente:

...promittentes calciamenta et vestimenta quaedam, et his venari eas et deducere ad hanc felicissimam civitatem et habere constitutas in suis habitationibus.

Es evidente el señuelo que utilizan los proxenetas que, sin lugar a dudas estaban bien organizados, a fin de poder acometer sus estratagemas basadas en falsas promesas de una vida de lujo para poder captar a mujeres en situación inerme. Al sufrir el traslado a la capital eran forzadas a ejercer la prostitución y entregadas a la lujuria, a cambio de percibir el dinero por los servicios; el prefacio, a tal efecto, señala que se celebraban contratos, evidentemente ilícitos, por los que eran obligadas por parte de los alcahuetes a ejercitar la prostitución sin un tiempo definido, sino como señala el texto hasta que les haya parecido bien quia usque ad tempus, quod eis placuerit. Esta industria 
del sexo era totalmente inmoral de hecho algunos intentaban separarlas y rescatarlas de esta explotación atroz tomándolas por matrimonio y pagando por ellas, pero los proxenetas se lo impedían.

Por si fuera poco, el texto comenta la explotación sexual infantil con niñas de diez años (puellas nec decimum agentes annum ad periculosam deponerent corruptionem) las cuales, evidentemente, constituían una mercancía sexual que no dejaban rescatar fácilmente por parte de aquellos que podían incluso unirse en matrimonio.

Como apuntábamos anteriormente, todo el prefacio realiza alusiones a denuncias de estas crueldades que conforman un apabullante negocio de "trata de seres vulnerables"; denuncias como señala la constitución secretas que fueron objeto de investigación, observando al mismo tiempo como se había ido extendiendo por la ciudad, lo cual reclamaba medidas perentorias a fin de librar a la ciudad de esta prostitución forzada por proxenetas que operaban en la ciudad.

Una cuestión importante a tener en cuenta en relación a la legislación del emperador Justiniano, continuado con la Nov. 14, es la influencia de su mujer Teodora (Garland, 1999, 18 ss) en la mejora de las condiciones de las mujeres más indefensas. Ella misma tenía interés en eliminar las desventajas de un colectivo mancillado y vilipendiado, de ahí que podemos ver los precedentes de políticas sociales dirigidas a mantener la moralidad y una mejora en el bienestar de los súbditos.

La Nov. 14 .1 establece como finalidad específica la limpieza de la ciudad de Constantinopla de las mafias que ejercían el lenocinio frente aquellos que comercializaban con seres humanos ya sea para explotarlos en lupanares, en casas privadas o en cualquier otro negocio, veamos el fragmento: "sancimus igitur omnes quidem secundum quod possint castitatem agere, quae etiam sola deo cum fiducia possibilis est hominum animas praesentare. Quia vero plurima sunt humana, cum arte et dolo et necessitate quaslibet ad talium luxuriant deduci omnibus prohibemus modis, et nulli fiduciam esse pascere meretricem et in domo habere mulieres aut publice prostituere ad luxuriam, et pro alio quodam negotio talia mercari, neque conscriptiones super hoc percipere neque fideiussores exigere nec aliquid tale agere, quod cogat miseras et invitas suam castitatem confundere, neque sperare quia licebit de cetero eis vestium 
donatione aut ornamentorum forsan aut alimenti decipere, ut etiam invitae sustineant. Non enim permittimus quicquam fieri tale, sed etiam nunc omnia talia breviter competenti cura disposuimus, statuentes etiam reddi eis omnem quam contigit cautionem occasione sceleris huius exponi; et neque permisimus scelestos lenones, si quid dederunt eis, hoc ab eis auferre: sed etiam ipsos lenones iussimus extra hanc fierifelicissimam civitatem tamquam pestiferos et communes vastatores castitatis factos, et liberas ancillasque requirentes et deducentes ad huiusmodi necessitatem et decipientes et habentes educatas ad universam confusionem. Praeconamus itaque quia, si quis de cetero praesumpserit invitam puellam sumere et habere ad necessitatem nutritam et fornicationis sibi deterentem quaestum, hunc necesse est ab spectabilibus praetoribus populi huius felicissimae civitatis comprehensum omnium novissima sustinere supplicia. Si enim pecuniarum eos furtorum et latrociniorum emendatores elegimus, quomodo non multo magis castitatis furtum et latrocinium eos cohercere permittimus? Si quis autem patiatur in sua domo quendam lenonem et huiusmodi praepositum operationis habere et haec denuntiata cognoscens non de domo sua expulerit, sciat etiam decem librarum auri sustinere poenam et circa ipsam periclitaturum habitationem. Si quis autem conscriptionem de cetero in talibus praesumpserit aut fideiussorem accipere, sciat nullam quidem se utililatem huiusmodi fideiussionis aut conscriptionis habere. Etenim fideiussor quidem obligatus non erit, conscriptio vero omnino invalida manebit; et ipse, sicut praediximus, in corpore supplicium sustinebit et magna hac longissime civitate expelletur. Mulieres itaque caste quidem vivere volumus et oramus, non autem invitas ad luxuriosam vitam deduci nec impie agere cogi. Omnino enim lenocinium et fieri prohibemus et factum punimus, praecipue quidem in hac felicissima civitate et in eius circuitu, nihilominus autem et in locis foris positis omnibus, et quae ab initio nostrae sunt reipublicae et quae nunc a domino deo donata sunt nobis, et maxime in illis, eo quod dei dona, quae circa nostram fecit rempublicam, volumus conservari pura ab omni tali necessitate, et domini dei circa nos munere esse et permanere digna. Credimus enim in domino deo etiam ex hoc nostro circa castitatem studio magnum fieri nostrae reipublicae incrementum, deo nobis omnia prospera per talia opera conferente".

La novela protege frente a cualquier atentado de la castidad de las mujeres víctimas de los lenonibus, cuyo comercio clandestino se ha ido extendiendo 
por todas partes. La providencia establece la expulsión de los mismos a los que menciona como pestilentes y corruptores de la castidad "pestiferos et communes vastatores castitatis" que tratan de engañar a mujeres que tratan de reclutar para sus fechorías ofreciéndoles regalos, vestidos y alimentos para arrastrarlas a la prostitución forzada. En igual sentido, se expresaba el prefacio de la novela como ya hemos visto. Pero además se añade la necesidad de evitar realizar el proxenetismo en viviendas privadas, conminando a su propietario al pago de diez libras de oro si consintiera tales hechos y no expulsase de la vivienda al proxeneta que ejercita su negocio ilícito. Además, son nulos los contratos celebrados que puedan favorecer cualquier actividad de mediación dentro de esta industria del sexo y la providencia obliga, además, al propietario de cualquier vivienda a denunciar los hechos prohibidos por la constitución, siendo responsable de la no expulsión del alcahuete que la utiliza.

La finalidad de la disposición es evidente al tratar de salvaguardar la sacralidad y honorabilidad de la ciudad a fin de preservarla de los actos impíos y del execrable negocio de la prostitución, procediendo al destierro y expulsión de los proxenetas. Para ello, también en el texto se habla de la necesidad de la difusión de su contenido para que pueda llegar al conocimiento de todos los ciudadanos, reclamando a su vez la colaboración de los mismos, como "nostri cives casta", para denunciar los comportamientos delictivos, los proxenetas implicados y aquellos que puedan ofrecer locales o celebrar contratos con éstos.

\section{Algunas notas conclusivas}

el fenómeno de la prostitución en el Derecho romano, como hemos tenido ocasión de comprobar, era inherente a una serie de comportamientos que execraba a la mujer en condición de vulnerabilidad, sometiéndola, muchas veces, a un trato degradante y a abusos sexuales.

A pesar de ello, fue un fenómeno que no sólo se toleró, sino también se promovió, siendo considerada necesaria y cumpliendo una labor social, de ahí la "doble moral" y la infamia necesaria que representó este oficio, en la que muchos preferían abandonarse a los placeres de la prostituta sin ningún tipo de carga o de responsabilidad; un remedio que preservaba la moralidad y fidelidad de las matronas ya que éstas últimas se convertían en pieza clave de la institución del matrimonio. 
Por otro lado, la intervención normativa, no deja de estar basada en una estrategia regulacionista al estar permitida y garantizar un orden moral establecido, aceptado como tal por el ciudadano romano, a pesar de que la prostituta en si misma estuviese discriminada y en la que confluía como rasgos: la indiferencia emocional, el pago y la promiscuidad.

La explotación implicaba lucrarse con la prostitución ya sea de esclavos o personas libres, como ya vimos $a b$ initio en D.3.2.4.2 referido al que hace lenocinio no solo el que hubiera tenido esclavos para lucrarse con su explotación sexual, sino también el que realizaba esta actividad con personas libres. A veces incluso obteniendo un lucro a través del lenocinium mariti, como vimos en D.48.5.2.2., castigado dentro de la lex iulia de adulteris, en la que el marido obtiene ganancias (quaestum) ejerciendo lenocinium con su propia mujer, comportamiento equiparable al ejercicio de la prostitución.

Además, hemos observado una constante en los intentos de reprimir no la prostitución sino la explotación sexual y lo que hoy entendemos como "trata de blancas", en en el texto de la Novela 14 de Justiniano, en la que, como hemos podido verificar, como se produce la concurrencia de los mismos elementos acumulativos del tipo penal que se exigen en la actualidad en base al art. 177 bis de nuestro código penal, en el modus operandi, como son:

Por un lado las acciones realizadas a través de la captación y reclutamiento, dos acciones que nos comenta la Novela 14 en relación a como se realizaba este tráfico yendo a las provincias y localizando a mujeres y niñas indefensas.

Por otro, el medio utilizado en relación a la artimaña y señuelo, en la Novela se habla del engaño a través de obsequios, vestidos y calzado, como forma de atraer a víctima. Lo cual hace entrever otro de los elementos que se tiene en cuenta en el derecho vigente y es la situación personal de las personas que se encuentran en estado inerme, basta con el hecho de que el tratante se aproveche de la situación de vulnerabilidad de la víctima, situación que ya se describe en la novela de Justiniano.

Finalmente, se observa de manera nítida el propósito del comercio de éstas mafias, como vimos en la novela que alude a la ciudad de Constantinopla, la explotación sexual en burdeles u otros recintos, a las cuales eran condenadas tanto las mujeres libres como esclavas captadas, 
e incluso niñas de diez años que evidentemente constituían una mercancía sexual que no dejaban rescatar fácilmente por parte de aquellos que podían incluso unirse en matrimonio.

En definitiva podemos concluir señalando que, a pesar de que la prostitución estaba aceptada socialmente, se perseguía a los lenones y su actividad comercial y de explotación ilícita que vilipendiaba a mujeres en situación de vulnerabilidad, un fenómeno que constituye una constante histórica y que por desgracia en la actualidad se sigue produciendo a pesar de los progresos notables en la lucha por las redes de prostitución organizada.

\section{Referencias bibliográficas}

Astolfi, R. (1965). Femina probosa, concubina, mater solitaria, "Studia et Documenta Historiae et Iuris" No. 31 (Roma), p. 15.

Biondi, B. (1952). Il diritto romano cristiano 2, Milano: Giuffrè.

Brasiello, U. (1937). La repressione penale in diritto romano, Napoli: ed. Jovene.

Bravo Bosch, Maj. (2017). Mujeres y símbolos en la Roma republicana: análisis jurídico-histórico de Lucrecia y Cornelia, Madrid: Dykinson. ISBN 9788491484455.

Catharine E. (1997). Unspeakable professions: public performance and prostitution in ancient Rome. In: J.P. Hallet, M.B. Skinner, Roman Sexualities, Princeton: Princeton University Press. ISBN 9780691011790.

Escutia Romero, R. (2010). La difamación pública en Derecho romano, "Revista jurídica de la Universidad Autónoma de Madrid” (RJUAM) No. 22, vol. 2. ISSN 1575-720X.

Fernández de Buján, A. (2017). La legislación de Augusto, Gerion, "Revista de Historia Antigua" No. 35, p. 87-104. ISSN 0213-0181.

Garland, L. (1999). Byzantine Empresses. Women and power in Byzantium AD. 527-1204, New york: Routledge. ISBN 0415146887.

Harper, K. (2013). From shame to sin. The Christian transformation of sexual morality in late antiquity, Cambridge: Harvard University Press. ISBN 9780674660014.

Knapp, R. (2011). Invisible Romans, (ed. Los olvidados de Roma. Prostitutas, forajidos, esclavos, gladiadores y gente corriente, trad. J. Paredes), Barcelona: Ariel. ISBN 9788434413955.

McGinn, Th.A.J. (1998). Prostitution, Sexuality and the Law in Ancient Rome, Oxford: University Press. ISBN 9780195161328. 
McGinn, Th.A.J. (2004). The Economy of Prostitution in the Roman World: A Study of Social History and the Brothel, Michigan: University of Michigan Press. ISBN 9780472113620.

Molina Torres, $M^{a}$.P. (2016). La matrona ideal según las fuentes literarias grecorromanas de finales de la República al s. I d.C., Espacio Tiempo y forma, II Historia Antigua 29, pp. 61. ISSN 1130-1082.

Montalbán López, R. (2016). El oficio más antiguo del mundo, "Revista de estudios de las mujeres" No. 4, p. 174. ISSN 2340-9630.

Neri, V. (1998). I marginali nell'occidente tardoantico. Poveri, infames e criminali nella nascente società cristiana, Bari: Edipuglia SRL. ISBN 9788872282083.

Panero Oria, P. (2009). La práctica de la prostitución como práctica de libertad sexual en la antigua Roma, en Identidades femeninas en un mundo plural, Sevilla: Colección Audem.

Panero Oria, P., (2001). Ius occidendi et ius accusandi en la lex iulia de adulteriis coercendis, Valencia: Tirant lo Blanch. ISBN 8484422852.

Quintilla Zanuy, M.Tª (2004). La interdicción lingüística en las denominaciones latinas para "prostituta», "Revista de Estudios Latinos (RELat)" No. 4, pp. 103-124. ISSN 1578-7486.

Rizelli, G. (1997). Lex lulia de adulteriis. Studi sulla disciplina di adulterium, lenocinium, stuprum, Lecce: Ed. Grifo. ISBN 9788872611081.

Robinson, O.F. (1992). Ancient Rome, City planning and administration, London: Routledge. ISBN 978-0415022347.

Rodríguez López, R. (2018). Trata de blancas y redes de prostitución forzosa, en No tan lejano. Una visión de la mujer romana a través de temas de actualidad, Valencia: Tirant lo Blanch. ISBN 9788417203702

Sitek, B. (1999). „Actiones popularem” w prawie rzymskim na przełomie republiki i pryncypatu. Szczecin: Wydawnictwo Uniwersytetu Szczecińskiego. ISBN 837241033X.

Sitek, B. (2004). Infamia w ustawodawstwie cesarzy rzymskich. Olsztyn: Wydawnictwo Uniwersytetu Warmińsko-Mazurskiego. ISBN 8372992347.

Vanoyeke, V. (1990). La prostitution en grèce et a rome, Paris: Realia. ISBN 9782251338101. 
